\title{
REVIEW
}

\section{Ixekizumab for the Treatment of Psoriasis: A Review of Phase III Trials}

Benjamin Farahnik • Kourosh Beroukhim • Tian Hao Zhu •

Michael Abrouk · Mio Nakamura - Rasnik Singh • Kristina Lee •

Tina Bhutani $\cdot$ John Koo

To view enhanced content go to www.dermtherapy-open.com Received: January 20, 2016 / Published online: February 24, 2016

(C) The Author(s) 2016. This article is published with open access at Springerlink.com

\section{ABSTRACT}

Introduction: Interleukin-17 inhibitors are the newest class of monoclonal antibodies approved by the US Food and Drug Administration for the treatment of psoriasis. Preclinical and Phase II studies of ixekizumab, a

Electronic supplementary material The online version of this article (doi:10.1007/s13555-016-0102-0) contains supplementary material, which is available to authorized users.

B. Farahnik $(\bowtie)$

University of Vermont College of Medicine,

Burlington, VT, USA

e-mail: Benjamin.farahnik@ucsf.edu

K. Beroukhim $\cdot$ R. Singh

University of California-Los Angeles, David Geffen

School of Medicine, Los Angeles, CA, USA

T. H. Zhu

University of Southern California Keck School of

Medicine, Los Angeles, CA, USA

M. Abrouk

University of California-Irvine, School of Medicine, Irvine, CA, USA

M. Nakamura - K. Lee - T. Bhutani · J. Koo Department of Dermatology, Psoriasis and Skin Treatment Center, University of California-San Francisco, San Francisco, CA, USA high-affinity anti-IL-17A monoclonal antibody, have proved promising.

Methods: We conducted an extensive literature search using the PubMed database to assess the efficacy and safety profile of ixekizumab. The search included the following key words: "psoriasis" and "IL-17" or "ixekizumab." We also reviewed citations within articles to identify relevant sources.

Results: By week 12, the percentage of patients achieving a 75\% improvement from baseline Psoriasis Area and Severity Index (PASI 75) was comparable among the three Phase III trials (UNCOVER-1， 89\%; UNCOVER-2， 90\%; UNCOVER-3, 87\%). Ixekizumab continued to be efficacious through 60 weeks of treatment. The safety profile of ixekizumab was favorable; the most frequently reported adverse events consisted of nasopharyngitis, upper respiratory tract infection, injection-site reaction, and headache.

Conclusion: Overall, ixekizumab demonstrated rapid clinical improvement and favorable short-term safety profile in Phase III trials. The results support ixekizumab as an effective therapeutic option for patients with moderate-to-severe plaque-type psoriasis. 
Keywords: Anti-interleukin-17; Biologics; Interleukin 17; Ixekizumab; Phase III; Psoriasis; UNCOVER

\section{INTRODUCTION}

Psoriasis is a common chronic inflammatory skin condition that affects $3-4 \%$ of the adult US population [1]. Surveys have shown that despite the availability of topical, oral, and systemic treatments, a substantial portion of patients with psoriasis remain undertreated relative to the severity of their disease, leading to high dissatisfaction rates [2]. Untreated psoriasis is associated with severe impairment in social, occupational, and overall well-being, with physical and emotional impact that increases with disease severity [2, 3]. Thus, new therapies with enhanced long-term efficacy and safety are needed by dermatologists for the treatment of moderate-to-severe psoriasis.

Ixekizumab is currently one of three biologic agents (along with secukinumab and brodalumab) that target the interleukin (IL)-17 cytokine pathway. IL-17 is a proinflammatory cytokine produced primarily by type 17 helper (TH17) T cells [4]. Specifically, IL-17A, one of the 6 homodimers of IL-17, is considered the most potent isoform in psoriasis development $[5,6]$ and exerts its effect by binding the IL-17 receptor subunit A (IL-17RA) [7]. Ixekizumab is a humanized monoclonal immunoglobulin $G$ (IgG) 4 antibody that acts by specifically binding to and inhibiting IL-17A, thus inhibiting the inflammatory changes culminating in psoriasis. IL-17 contributes a role in the activation and recruitment of neutrophils, the blockade of neutrophil apoptosis, and the stimulation of psoriasis angiogenesis [6, 8-10]. Evidence of elevated levels of IL-17 in psoriatic lesions and in the serum of patients with psoriasis further support the role of IL-17 in the pathophysiology of psoriasis [11-15].

In the following article, we review the results of the pivotal Phase III trials regarding the efficacy and safety of ixekizumab in patients with moderate-to-severe plaque psoriasis. The co-primary endpoints examined include at least a $75 \%$ reduction in psoriasis area and severity index (PASI 75) and static physician global assessment (sPGA) of 0 (clear) or 1 (almost-clear) on a 5-point scale by week 12 of treatment. sPGA is a tool used by clinicians to document their impression of disease severity, with scores ranging from 0 (clear) to 4 (severe disease). We also examined the long-term efficacy, up to 60 weeks, in the clinical trials that have been completed to date.

\section{METHODS}

We reviewed the published results of the Phase III clinical trials for ixekizumab to determine the percentage of patients with psoriasis who had a positive response to the therapy. To identify all the studies that addressed ixekizumab, we performed an English language literature search from January 2003 to September 2015 using PubMed with any of the following key words: "ixekizumab" and "psoriasis" or "IL-17" and "psoriasis". We also reviewed citations within articles to identify relevant resources and examined recent dermatologic posters for preliminary data as well. Pooled measures of efficacy and incidence of adverse events for each medication were calculated by tabulating values from independently conducted studies.

This article is based on previously conducted studies and does not involve any new studies of 
human or animal subjects performed by any of the authors.

\section{RESULTS}

Three major Phase III clinical trials, UNCOVER-1, UNCOVER-2, and UNCOVER-3 (ClinicalTrials.gov identifiers: NCT01474512, NCT01597245, and NCT01646177, respectively) were conducted to evaluate efficacy and safety of different dosing frequencies of ixekizumab compared to placebo [16, 17]. UNCOVER-2 and UNCOVER-3 also compared ixekizumab to etanercept. The comparisons in baseline demographics are shown in Table 1, while the results from each of these trials are displayed in Table 2. The differences between the endpoints at week 12 are recorded in Table 3.

\section{UNCOVER-1}

\section{Study Design}

This was a prospective, double-blind, multicenter trial that consisted of 1296 patients randomly distributed in a 1:1:1 ratio to receive $80 \mathrm{mg}$ ixekizumab every 2 weeks (Q2W), $80 \mathrm{mg}$ ixekizumab every 4 weeks (Q4W), or placebo, respectively [16]. Patients in the ixekizumab groups received a $160 \mathrm{mg}$ starting dose followed by $80 \mathrm{mg}$ Q2W or Q4W. All patients were given two subcutaneous injections (ixekizumab or placebo) at week 0 and one subcutaneous injection (ixekizumab or placebo) at week 2, 4, 6, 8, and 10 . The study incorporated the co-primary endpoints of PASI 75 and sPGA 0 or 1 at week 12. PASI 90 and PASI 100 were included as secondary endpoints in the study. At 12 weeks, patients who responded to ixekizumab treatment (identified as sPGA 0/1 at week 12) were re-randomized to receive placebo, ixekizumab $80 \mathrm{mg}$ Q4W, or ixekizumab $80 \mathrm{mg}$ every 12 weeks and followed for an additional 48 weeks.

\section{Efficacy}

By week 12, the trial demonstrated statistically significant superiority of ixekizumab $80 \mathrm{mg}$ Q2W and ixekizumab $80 \mathrm{mg}$ Q4W over placebo. The proportion of patients achieving PASI 75 was $89.1 \%$ and $82.6 \%$ for ixekizumab Q2W and Q4W, respectively, compared to 3.9\% in those who took placebo $(P<0.001$ compared to placebo). The percentage achieving sPGA 0 or 1 was $81.8 \%$ and $76.4 \%$ for ixekizumab Q2W and $\mathrm{Q} 4 \mathrm{~W}$, respectively, compared to $3.2 \%$ in those who took placebo $(P<0.001$ compared to placebo). Both dosage regimens of ixekizumab were similarly statistically superior to placebo in terms of PASI 90 and PASI $100 \quad(P<0.001$ compared to placebo; Table 2). The extended data from UNCOVER-1 revealed that this trend in results was maintained through 60 weeks with $72.9 \%$ of ixekizumab-treated responders maintaining sPGA $0 / 1,77.7 \%$ maintaining or achieving PASI 75 , and $52.0 \%$ maintaining or achieving PASI 100.

\section{Adverse Events}

At 12 weeks, a greater proportion of patients receiving ixekizumab $80 \mathrm{mg}$ Q2W and $80 \mathrm{mg}$ Q4W experienced adverse events $(59.4 \%$ and $61.1 \%$, respectively) or infections $(28.6 \%$ and $29.6 \%$, respectively), compared to placebo (adverse events: $48.7 \%$, infections: $24.6 \%$ ). The most common adverse events were nasopharyngitis and injection-site reaction. Most adverse events brought on by treatment were mild or moderate in severity with most patients continuing treatment with 


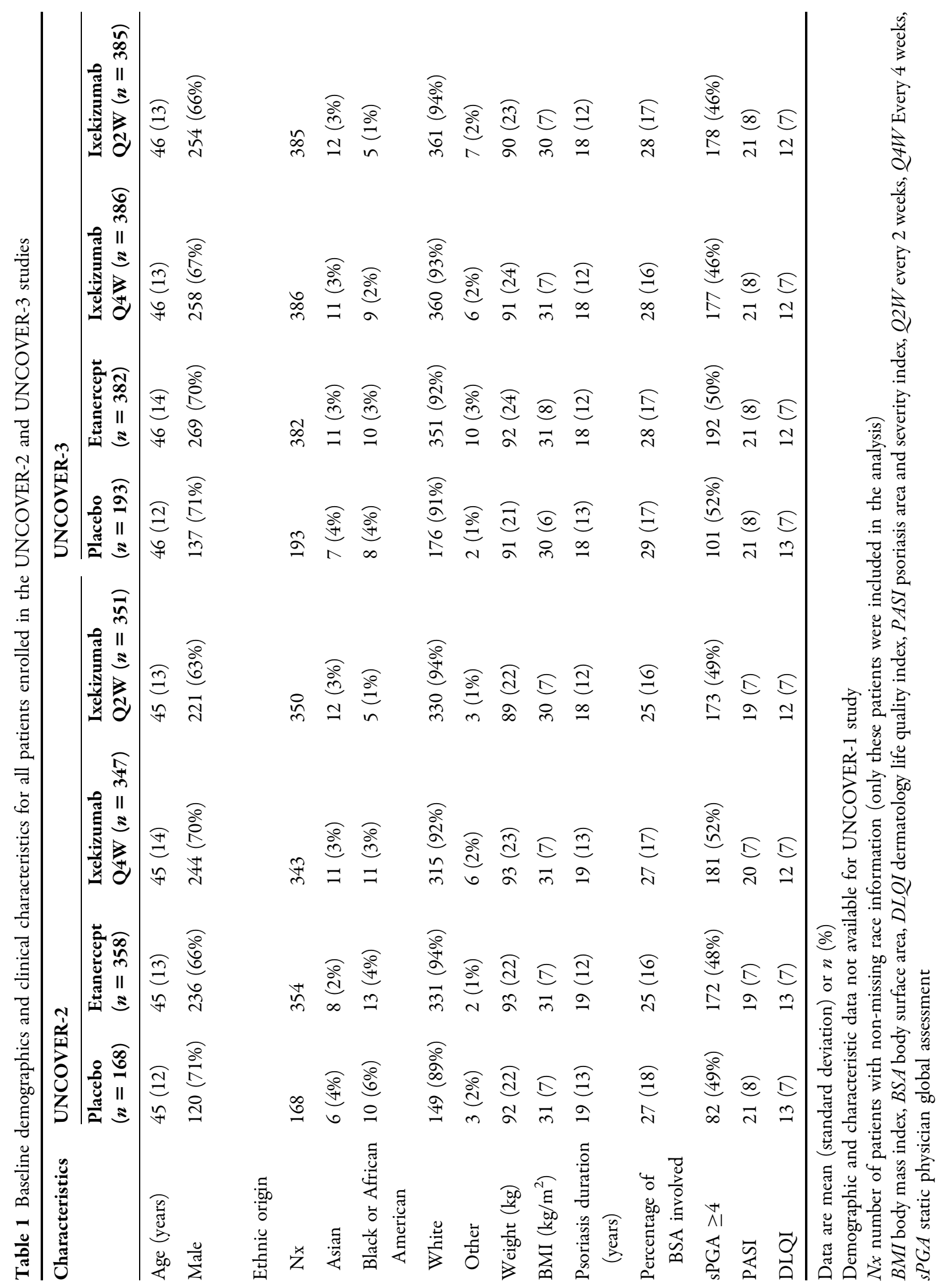


Table 2 Primary and secondary endpoints at week 12 for ixekizumab compared to placebo and etanercept

\begin{tabular}{llllll}
\hline End point & Study & Ixekizumab Q2W & Ixekizumab Q4W & Placebo & Etanercept 50 mg \\
\hline PASI 75 & UNCOVER-1 & $89.1 \%(386 / 433)^{\mathrm{a}}$ & $82.6 \%(357 / 432)^{\mathrm{a}}$ & $3.9 \%(17 / 431)$ & - \\
& UNCOVER-2 & $89.7 \%(315 / 351)^{\mathrm{b}, \mathrm{c}}$ & $77.5 \%(269 / 347)^{\mathrm{b}, \mathrm{c}}$ & $2.4 \%(4 / 168)$ & $41.6 \%(149 / 358)^{\mathrm{c}}$ \\
& UNCOVER-3 & $87.3 \%(336 / 385)^{\mathrm{b}, \mathrm{c}}$ & $84.2 \%(325 / 386)^{\mathrm{b}, \mathrm{c}}$ & $7.3 \%(14 / 193)$ & $53.4 \%(204 / 382)^{\mathrm{c}}$ \\
\multirow{2}{*}{ PASI 90 } & UNCOVER-1 & $70.9 \%(307 / 433)^{\mathrm{a}}$ & $64.6 \%(279 / 432)^{\mathrm{a}}$ & $0.5 \%(2 / 431)$ & - \\
& UNCOVER-2 & $70.7 \%(248 / 351)^{\mathrm{b}, \mathrm{c}}$ & $59.7 \%(207 / 347)^{\mathrm{b}, \mathrm{c}}$ & $0.6 \%(1 / 168)$ & $18.7 \%(67 / 358)^{\mathrm{c}}$ \\
& UNCOVER-3 & $68.1 \%(262 / 385)^{\mathrm{b}, \mathrm{c}}$ & $65.3 \%(252 / 386)^{\mathrm{b}, \mathrm{c}}$ & $3.1 \%(6 / 193)$ & $25.7 \%(98 / 382)^{\mathrm{c}}$ \\
\multirow{2}{*}{ PASI 100 } & UNCOVER-1 & $35.3 \%(153 / 433)^{\mathrm{a}}$ & $33.6 \%(145 / 432)^{\mathrm{a}}$ & $0.0 \%(0 / 431)$ & - \\
& UNCOVER-2 & $40.5 \%(142 / 351)^{\mathrm{b}, \mathrm{c}}$ & $30.8 \%{ }^{\mathrm{b}, \mathrm{c}}(107 / 347)^{\mathrm{b}, \mathrm{c}}$ & $0.6 \%(1 / 168)$ & $5.3 \%(19 / 358)^{\mathrm{c}}$ \\
& UNCOVER-3 & $37.7 \%(145 / 385)^{\mathrm{b}, \mathrm{c}}$ & $35.0 \%{ }^{\mathrm{b}, \mathrm{c}}(135 / 386)^{\mathrm{b}, \mathrm{c}}$ & $0.0 \%(0 / 193)$ & $7.3 \%{ }^{\mathrm{c}}(28 / 382)^{\mathrm{c}}$ \\
\multirow{2}{*}{ sPGA 0/1 } & UNCOVER-1 & $81.8 \%(354 / 433)^{\mathrm{a}}$ & $76.4 \%(330 / 432)^{\mathrm{a}}$ & $3.2 \%(14 / 431)$ & - \\
& UNCOVER-2 & $83.2 \%(292 / 351)^{\mathrm{b}, \mathrm{c}}$ & $72.9 \%(253 / 347)^{\mathrm{b}, \mathrm{c}}$ & $2.4 \%(4 / 168)$ & $36.0 \%(129 / 358)^{\mathrm{c}}$ \\
& UNCOVER-3 & $80.5 \%(310 / 385)^{\mathrm{b}, \mathrm{c}}$ & $75.4 \%(291 / 386)^{\mathrm{b}, \mathrm{c}}$ & $6.7 \%(13 / 193)$ & $41.6 \%(159 / 382)^{\mathrm{c}}$ \\
\multirow{2}{*}{ DLQI 0/1 } & UNCOVER-1 & - & - & - & - \\
& UNCOVER-2 & $64.1 \%(225 / 351)^{\mathrm{b}, \mathrm{c}}$ & $59.9 \%(208 / 347)^{\mathrm{b}, \mathrm{c}}$ & $6.0 \%(10 / 168)$ & $33.8 \%(121 / 358)^{\mathrm{c}}$ \\
& UNCOVER-3 & $64.7 \%(249 / 385)^{\mathrm{b}, \mathrm{c}}$ & $63.7 \%(246 / 386)^{\mathrm{b}, \mathrm{c}}$ & $7.8 \%(15 / 193)$ & $43.7 \%(167 / 382)^{\mathrm{c}}$ \\
\hline
\end{tabular}

Disclaimer: These data were tabulated from independent studies that were not conducted in a head-to-head manner $D L Q I$ dermatology life quality index, $P A S I$ psoriasis area and severity index, $Q 2 W$ every 2 weeks, $Q 4 W$ every 4 weeks, sPGA static physician global assessment

a $P<0.001$ for the comparison with placebo

b $P<0.0001$ for the comparison with etanercept

c $P<0.0001$ for the comparison with placebo

d $P=0.0082$ for the comparison of etanercept with placebo

ixekizumab. The proportions of patients with a Candida infection at 12 weeks were $0.9 \%$ and $0.6 \%$ for ixekizumab Q2W and ixekizumab Q4W, respectively, compared to $0.5 \%$ for placebo. The rates of serious adverse events at 12 weeks were $1.4 \%, 2.8 \%$, and $1.2 \%$ for patients on ixekizumab Q2W, ixekizumab Q4W, or placebo, respectively. However, this data set should be interpreted with caution as results are preliminary and have not yet been peer reviewed. Additionally, comparisons in adverse events are not statistically significant, as the studies are powered to detect differences in efficacy rather than rates of adverse events.

\section{UNCOVER-2}

\section{Study Design}

This was a prospective, double-blind, multicenter study that consisted of 1224 patients randomly distributed in a 2:2:2:1 ratio to receive $80 \mathrm{mg}$ ixekizumab Q2W, $80 \mathrm{mg}$ ixekizumab Q4W, etanercept $50 \mathrm{mg}$ twice 
Table 3 Difference between endpoints at week 12 for ixekizumab compared to placebo and etanercept, and etanercept compared to placebo

\begin{tabular}{|c|c|c|c|c|c|c|}
\hline \multirow{2}{*}{$\begin{array}{l}\text { End } \\
\text { point }\end{array}$} & \multirow[t]{2}{*}{ Study } & \multicolumn{5}{|l|}{ Difference $\left(\mathbf{C I}^{\mathbf{a}}\right)$} \\
\hline & & $\begin{array}{l}\text { Ixekizumab } \\
\text { Q2W vs. } \\
\text { placebo }\end{array}$ & $\begin{array}{l}\text { Ixekizumab } \\
\text { Q2W vs. } \\
\text { etanercept }\end{array}$ & $\begin{array}{l}\text { Ixekizumab } \\
\text { Q4W vs. } \\
\text { placebo }\end{array}$ & $\begin{array}{l}\text { Ixekizumab } \\
\text { Q4W vs. } \\
\text { etanercept }\end{array}$ & $\begin{array}{l}\text { Etanercept } \\
50 \mathrm{mg} \text { vs. } \\
\text { placebo }\end{array}$ \\
\hline \multirow[t]{3}{*}{ PASI 75} & UNCOVER-1 & - & - & - & - & - \\
\hline & UNCOVER-2 & $87.4(82.9-91.8)$ & $48.1(41.2-55.0)$ & $75.1(69.5-80.8)$ & $35.9(28.2-43.6)$ & $39.2(32.8-45.6)$ \\
\hline & UNCOVER-3 & $80.0(74.4-85.7)$ & $33.9(27.0-40.7)$ & $76.9(71.0-82.8)$ & $30.8(23.7-37.9)$ & $46.1(39.1-53.2)$ \\
\hline \multirow[t]{3}{*}{ PASI 90} & UNCOVER-1 & - & - & - & - & - \\
\hline & UNCOVER-2 & $70.1(64.5-75.7)$ & $51.9(44.8-59.1)$ & $59.1(53.0-65.1)$ & $40.9(33.4-48.4)$ & $18.1(13.3-22.9)$ \\
\hline & UNCOVER-3 & $64.9(58.9-71.0)$ & $42.4(35.1-49.7)$ & $62.2(56.1-68.3)$ & $39.6(32.2-47.0)$ & $22.5(16.8-28.3)$ \\
\hline \multirow[t]{3}{*}{ PASI 100} & UNCOVER-1 & - & - & - & - & - \\
\hline & UNCOVER-2 & $39.9(33.8-45.9)$ & $35.1(28.7-41.6)$ & $30.2(24.5-36.0)$ & $25.5(19.4-31.7)$ & $4.7(1.7-7.7)$ \\
\hline & UNCOVER-3 & $37.7(32.1-43.2)$ & $30.3(24.0-36.6)$ & $35.0(29.5-40.4)$ & $27.6(21.4-33.9)$ & $7.3(4.3-10.3)$ \\
\hline \multirow[t]{3}{*}{ sPGA $0 / 1$} & UNCOVER-1 & - & - & - & - & - \\
\hline & UNCOVER-2 & $80.8(75.6-86.0)$ & $47.2(39.9-54.4)$ & $70.5(64.6-76.5)$ & $36.9(29.1-44.7)$ & $33.7(27.4-39.9)$ \\
\hline & UNCOVER-3 & $73.8(67.7-79.9)$ & $38.9(31.7-46.1)$ & $68.7(62.3-75.0)$ & $33.8(26.3-41.3)$ & $34.9(27.9-41.8)$ \\
\hline \multirow[t]{3}{*}{ DLQI 0/1 } & UNCOVER-1 & - & - & - & - & - \\
\hline & UNCOVER-2 & $58.2(51.1-65.2)$ & $30.3(22.3-38.3)$ & $54.0(46.8-61.2)$ & $26.1(18.0-34.3)$ & $27.8(20.9-34.8)$ \\
\hline & UNCOVER-3 & $56.9(49.9-63.9)$ & $21.0(13.1-28.8)$ & $56.0(49.0-62.9)$ & $20.0(12.1-27.9)$ & $35.9(28.8-43.1)$ \\
\hline
\end{tabular}

Disclaimer: These data were tabulated from independent studies that were not conducted in a head-to-head manner $C I$ confidence interval, $D L Q I$ dermatology life quality index, $P A S I$ psoriasis area and severity index, $Q 2 W$ every 2 weeks, $Q 4 W$ every 4 weeks, $s P G A$ static physician global assessment

${ }^{a} 97.5 \% \mathrm{CI}$

weekly, or placebo, respectively [17]. As in UNCOVER-1, patients in the ixekizumab groups received a $160 \mathrm{mg}$ starting dose followed by $80 \mathrm{mg}$ dosing Q2W or Q4W. Those receiving etanercept or placebo for etanercept were given twice weekly subcutaneous injections from 0 to 11 weeks, while those given ixekizumab or placebo for ixekizumab were administered two subcutaneous injections at week 0 (for the starting dose) and one subcutaneous injection at week 2, 4, 6, 8, and 10 . The trial incorporated the co-primary endpoints of PASI 75 and sPGA 0 or 1 at week 12. PASI 90, PASI 100, itch numeric rating scale, and Dermatology Life Quality Index (DLQI) were included as secondary endpoints in the study.

\section{Efficacy}

At 12 weeks, the study demonstrated statistically significant superiority of ixekizumab $80 \mathrm{mg} \quad \mathrm{Q} 2 \mathrm{~W}$ and ixekizumab $80 \mathrm{mg}$ Q4W over placebo. The proportion of patients achieving PASI 75 was $89.7 \%$ and $77.5 \%$ for ixekizumab Q2W and Q4W, 
respectively, compared to $2.4 \%$ in those who took placebo $(P<0.0001$ compared to placebo). The percentage achieving sPGA 0 or 1 was 83.2\% and $72.9 \%$ for ixekizumab Q2W and $\mathrm{Q} 4 \mathrm{~W}$, respectively, compared to $2.4 \%$ in those who took placebo $(P<0.0001$ compared to placebo). Both dosage regimens of ixekizumab were similarly statistically superior to placebo in terms of PASI 90, PASI 100, and DLQI $(P<0.0001$ compared to placebo; Table 2). In comparison to etanercept $50 \mathrm{mg}$ twice weekly, ixekizumab $80 \mathrm{mg}$ Q2W and Q4W were shown to be statistically superior in terms of proportion of patients reaching PASI 75 and sPGA 0 or 1 at week $12(P<0.0001$ compared to etanercept).

\section{Adverse Events}

At 12 weeks, a greater proportion of patients receiving ixekizumab $80 \mathrm{mg}$ Q2W and $80 \mathrm{mg}$ Q4W experienced treatment emergent adverse events $(61.7 \%$ and $58.8 \%$, respectively) or infections $(29.7 \%$ and $28.8 \%$, respectively), compared to placebo (adverse events: 53.3\%, infections: $27.5 \%$ ). The most common adverse events were nasopharyngitis, injection-site reaction, and headache. Most adverse events brought on by treatment were mild or moderate in severity with most patients continuing treatment with ixekizumab. The proportions of patients with a Candida infection at 12 weeks were $1.5 \%$ and $0.3 \%$ for ixekizumab Q2W and ixekizumab Q4W, respectively, compared to $0.6 \%$ for placebo. All Candida infections were mild to moderate in intensity and resolved without discontinuation of treatment. The rates of serious adverse events at 12 weeks were $1.4 \%$, $2.3 \%$, and $1.2 \%$ for patients on ixekizumab Q2W, ixekizumab Q4W, or placebo, respectively. At 12 weeks, neutropenia was reported in $8.6 \%$ of patients taking ixekizumab
Q2W and 7.6\% of patients taking ixekizumab $\mathrm{Q} 4 \mathrm{~W}$, compared to $4.8 \%$ of patients taking placebo. Cases of neutropenia were mild and transient, without associated infections. It is important to note that comparisons in adverse events are not statistically significant, as the studies are powered to detect differences in efficacy rather than rates of adverse events.

\section{UNCOVER-3}

\section{Study Design}

This study employed the same design method as UNCOVER-2, with a trial that consisted of 1346 patients randomly distributed in a 2:2:2:1 ratio for $80 \mathrm{mg}$ ixekizumab Q2W, $80 \mathrm{mg}$ ixekizumab Q4W, etanercept $50 \mathrm{mg}$ twice weekly, or placebo, respectively [17]. Like the previous UNCOVER trials, patients in the ixekizumab groups received a $160 \mathrm{mg}$ starting dose followed by $80 \mathrm{mg}$ dosing Q2W or Q4W. Those receiving etanercept or placebo for etanercept were given twice weekly subcutaneous injections from 0 to 11 weeks, while those given ixekizumab or placebo for ixekizumab were administered two subcutaneous injections at week 0 (for the starting dose) and one subcutaneous injection at week 2, 4, 6, 8, and 10 . The study incorporated the same co-primary and secondary endpoints as UNCOVER-2.

\section{Efficacy}

Like the previous trials, UNCOVER-3 also showed statistically significant superiority of ixekizumab $80 \mathrm{mg}$ Q2W and ixekizumab $80 \mathrm{mg}$ Q4W over placebo. The proportion of patients reaching PASI 75 was $87.3 \%$ and $84.2 \%$ for ixekizumab Q2W and Q4W, respectively, 
compared to $7.3 \%$ in those who took placebo $(P<0.0001$ compared to placebo). The percentage achieving sPGA 0 or 1 was $80.5 \%$ and $75.4 \%$ for ixekizumab Q2W and Q4W, respectively, compared to $6.7 \%$ in those who took placebo $(P<0.0001$ compared to placebo). Both ixekizumab regimens were similarly statistically superior to placebo in terms of PASI 90, PASI 100, and DLQI $(P<0.0001$ compared to placebo; Table 2). As in UNCOVER-2 ixekizumab $80 \mathrm{mg}$ Q2W and Q4W were shown to be statistically superior to etanercept $50 \mathrm{mg}$ twice weekly, in terms of proportion of patients reaching PASI 75 and sPGA 0 or 1 at week $12(P<0.0001$ compared to etanercept).

\section{Adverse Events}

By 12 weeks, a greater proportion of patients receiving ixekizumab $80 \mathrm{mg}$ Q2W and $80 \mathrm{mg}$ Q4W experienced treatment emergent adverse events $(53.4 \%$ and $56.3 \%$, respectively) or infections $(21.4 \%$ and $23.0 \%$, respectively), compared to placebo (adverse events: 36.3\%, infections: $14.0 \%$ ). The most common adverse events were nasopharyngitis, injection-site reaction, upper respiratory tract infection, and headache. Most adverse events brought on by treatment were mild or moderate in severity with most patients continuing treatment with ixekizumab. The proportions of patients with Candida infection at 12 weeks were $1.8 \%$ and $0.8 \%$ for ixekizumab Q2W and ixekizumab $\mathrm{Q} 4 \mathrm{~W}$, respectively, compared to $0.5 \%$ for placebo. All Candida infections were mild to moderate in intensity and resolved without discontinuation of treatment. The rates of serious adverse events at 12 weeks were 2.3, 1.6, and 2.6\% for patients on ixekizumab Q2W, ixekizumab Q4W, or placebo, respectively. At 12 weeks, neutropenia was reported in $8.9 \%$ of patients taking ixekizumab Q2W and 9.5\% of patients taking ixekizumab Q4W, compared to $1.0 \%$ of patients taking placebo. Cases of neutropenia were mild and transient, without associated infections. Important to note, comparisons in adverse events are not statistically significant, as the studies are powered to detect differences in efficacy rather than rates of adverse events.

\section{POOLED RESULTS}

\section{Efficacy}

By week 12, each of the three studies demonstrated statistically significant superiority of ixekizumab $80 \mathrm{mg}$ dosed Q2W and ixekizumab $80 \mathrm{mg}$ dosed Q4W over placebo $(P<0.001$ for all groups compared to placebo). Within these studies, the pooled proportion of patients reaching PASI 75 was $88.7 \%$ and $81.6 \%$ for ixekizumab $80 \mathrm{mg}$ Q2W and ixekizumab $80 \mathrm{mg}$ Q4W, respectively, compared to $4.4 \%$ in those who took placebo (Fig. 1). The pooled percentages of patients achieving sPGA 0 or 1 were $81.8 \%$ and $75.0 \%$ for ixekizumab $80 \mathrm{mg}$ Q2W and ixekizumab $80 \mathrm{mg}$ Q4W, respectively, compared to $3.9 \%$ in those who took placebo. Ixekizumab was similarly superior to placebo in terms of PASI 90 and PASI 100 (Fig. 1).

\section{Adverse Events}

The pooled proportion of patients who experienced adverse events at 12 weeks in the three studies comparing ixekizumab to placebo was $54.8 \%$ among patients taking ixekizumab $80 \mathrm{mg}$ Q2W, 58.8\% among patients taking ixekizumab $80 \mathrm{mg}$ Q4W, and 46.8\% among patients on placebo. The pooled proportion of patients experiencing a general infection or 


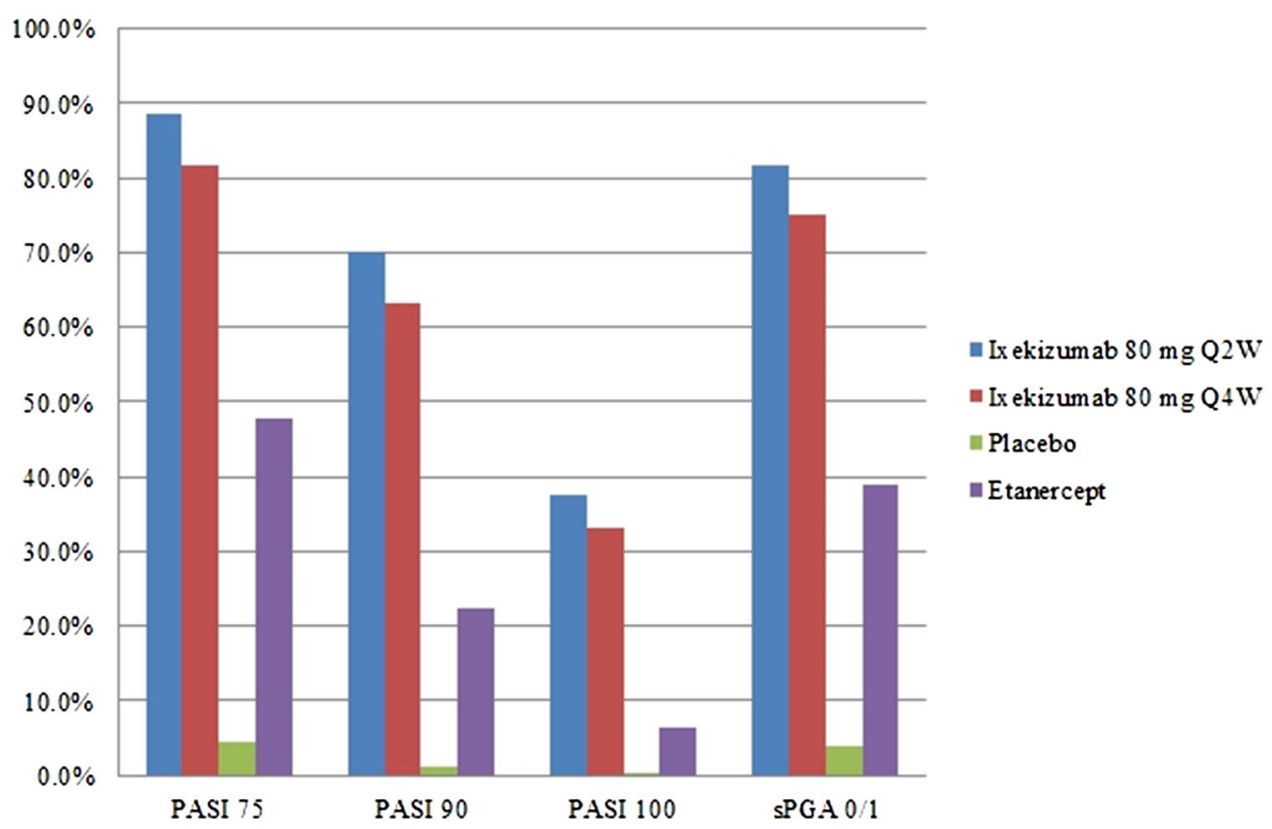

Fig. 1 Percentage of patients achieving PASI 75, PASI 90, PASI 100, and sPGA 0 or 1 at the most efficacious Phase III dosage for each drug, week 12. Disclaimer: Data were tabulated from independent studies that were not

specifically a Candida infection was $26.9 \%$ and $1.4 \%$ for those on ixekizumab Q2W, respectively, and $27.5 \%$ and $0.6 \%$ for those on ixekizumab Q4W, respectively. Of patients on placebo, 22.8\% experienced a general infection and $0.5 \%$ a Candida infection. For the UNCOVER-2 and UNCOVER-3 trials, the pooled proportion of patients who experienced neutropenia were $8.8 \%$ and $8.5 \%$ for ixekizumab $80 \mathrm{mg}$ Q2W and ixekizumab $80 \mathrm{mg}$ Q4W, respectively, compared to $2.8 \%$ for placebo.

\section{DISCUSSION}

The results of Phase III clinical trials reinforce the theory that ixekizumab is an effective agent in the treatment of plaque-type psoriasis. At week 12, the proportion of patients achieving PASI 75 or sPGA scores of 0 or 1 was comparable between each respective dosage among the three trials and far superior to the portion of conducted in a head-to-head manner. PASI psoriasis area and severity index, $Q 2 W$ every 2 weeks, $Q 4 W$ every 4 weeks, $s P G A$ static physician global assessment

patients that received placebo (Table 1; Fig. 1). The extended data from UNCOVER-1 suggest that the trend of positive results was maintained through 60 weeks of treatment. In UNCOVER-2 and UNCOVER-3, ixekizumab $80 \mathrm{mg}$ Q2W and $80 \mathrm{mg}$ Q4W were found to perform significantly better than etanercept $50 \mathrm{mg}$ twice weekly, a contemporary biologic agent currently approved by the US Food and Drug Administration (FDA) for the treatment of moderate-to-severe plaque psoriasis., The superiority of ixekizumab is most pronounced in terms of the proportion of patients who achieve PASI 90 and PASI 100 (Table 1). This is significant because these efficacy endpoints are more substantial than PASI 75 from a patient perspective, as demonstrated by a study finding that patients who achieve PASI 90 or PASI 100 experience greater improvement in quality of life than PASI 75 responders [18]. The availability of this novel, highly efficacious 
class of biologic medication offers new hope for patients whose psoriasis remains recalcitrant to the older biologic agents.

Within the context of these Phase III trials of ixekizumab, the most common adverse events included nasopharyngitis, upper respiratory tract infection, injection-site reaction, and headache. Most adverse events were mild or moderate in severity. A small portion of patients (less than 9\%) experienced low-grade neutropenia while on ixekizumab $80 \mathrm{mg}$ Q2W or ixekizumab $80 \mathrm{mg}$ Q4W, though the cases were transient and without associated infections. Based on findings in patients with genetic IL-17 immunity deficiencies, anti-IL-17 agents may theoretically increase the risk for mucocutaneous candidiasis infection [19, 20]. In the trials reviewed here, mild and moderate Candida infections were more frequent among patients taking ixekizumab than placebo. However, all Candida infections were mild to moderate in intensity and resolved without discontinuation of treatment.

There are currently three IL-17 pathway inhibitors that have completed Phase III testing: secukinumab, brodalumab, and ixekizumab. There are several differences among these drugs with potential clinical implications. With regards to frequency of injections, ixekizumab provides a more favorable option with only 4 syringes applied by the end of the first month for the $80 \mathrm{mg}$ Q2W regimen, compared to secukinumab that requires 10 syringes applied by the end of the first month for the $300 \mathrm{mg}$ regimen (both dosing regimens are the highest for the respective drug). With regards to brodalumab, the number of syringes involves in the first 4 weeks is similar to ixekizumab in that only four injections of single syringes are needed. However, in the maintenance phase, which can go on for years, brodalumab is unique in that its most efficacious dosage requires every other week injection, as opposed to secukinumab and ixekizumab, both of which only require monthly maintenance injections.

Secukinumab, currently the only agent among the three that is FDA approved, and brodalumab are fully human monoclonal antibodies, whereas ixekizumab is a humanized antibody. This difference may affect immunologic reactivity, as fully human antibodies are theorized to result in a smaller degree of immunogenicity relative to humanized antibodies [21]. Clinically, a higher degree of immunogenicity may result in long-term loss of efficacy secondary to antibody production against the drug [22]. However, studies have found similar immunogenicity among high scoring humanized antibodies, such as ixekizumab, and fully human antibodies [21, 23]. A high scoring humanized antibody is an antibody that contains nonhuman regions, yet still acts almost identically to a fully human antibody in studies. Furthermore, ixekizumab is an IgG4 isotype, a bispecific molecule in vivo that would have the potential for drug reactions. However, ixekizumab has been shown to be functionally monovalent, meaning that it does not have the same potential for drug reactions as other IgG4 isotypes [24]. Finally, ixekizumab and secukinumab are antibodies against IL-17A, whereas brodalumab is an antibody that targets the IL-17 receptor, thus antagonizing all IL-17 subtypes. Thus far, there have been no head-to-head comparisons of these drugs to directly verify efficacy and safety of one agent over the other.

In addition to treating the cutaneous symptoms of psoriasis, ixekizumab as an IL-17 pathway inhibitor may provide additional systemic benefits. Between 5\% and 30\% of patients with psoriasis suffer from concomitant psoriatic arthritis, a progressive 
and irreversible condition that merits systemic therapy $[25,26]$. Increased levels of IL-17 and IL-17 receptor are present in the synoviocytes and synovial fluid of psoriatic arthritis patients compared to those of patients with osteoarthritis [27, 28]. Accordingly, a Phase III clinical trial demonstrated that ixekizumab was statistically superior to placebo in the treatment of patients with active psoriatic arthritis at 24 weeks, as measured by the proportion of patients achieving an American College of Rheumatology 20\% improvement response (ACR20) [29]. Recent epidemiologic studies also suggest that treating the systemic inflammatory state associated with psoriasis leads to a reduction of cardiovascular events such as myocardial infarction and stroke [30]. On a molecular level, elevated levels of IL-17 have been measured in atherosclerotic plaques [31], which are thought to act in coordination with other proinflammatory cytokines in plaque formation [32]. Moreover, elevated levels of IL-17 are present in patients who suffer from unstable angina and acute myocardial infarction [33]. Taken together, these findings suggest that antagonizing the IL-17 pathway may serve to alleviate the symptoms of psoriatic arthritis and reduce the risk of cardiovascular events in patients with psoriasis [34].

\section{CONCLUSIONS}

Ixekizumab has yielded promising data in terms of efficacy and safety for the treatment of chronic plaque psoriasis. Ixekizumab $80 \mathrm{mg}$ Q2W and ixekizumab $80 \mathrm{mg}$ Q4W have demonstrated to be more efficacious in terms of PASI 75, PASI 90, and PASI 100 at week 12 as compared with etanercept $50 \mathrm{mg}$ twice weekly or placebo. Further data from open-label extension studies are necessary to confirm the favorable efficacy and safety profile of this agent demonstrated in the Phase III trials.

\section{ACKNOWLEDGMENTS}

No funding or sponsorship was received for publication of this article. All named authors meet the International Committee of Medical Journal Editors (ICMJE) criteria for authorship for this manuscript, take responsibility for the integrity of the work as a whole, and have given final approval for the version to be published.

Disclosures. Dr. John Koo is a speaker for AbbVie, Leo, and Celgene. Dr. Koo conducts research for Amgen, Janssen, Novartis, Photomedex, Galderma, Pfizer and Merck. Dr. Tina Bhutani is an advisor for Cutanea. Dr. Bhutani conducts research for Abbvie, Janssen, and Merck. Dr. Koo and Dr. Bhutani have no stocks, employment or board memberships with any pharmaceutical company. Mr. Benjamin Farahnik, Mr. Kourosh Beroukhim, Dr. Mio Nakamura, Mr. Michael Abrouk, Mr. Tian Hao Zhu, Ms. Rasnik Singh, and Ms. Kristina Lee have nothing to disclose.

Compliance with Ethics Guidelines. This article is based on previously conducted studies and does not involve any new studies of human or animal subjects performed by any of the authors.

Open Access. This article is distributed under the terms of the Creative Commons Attribution-NonCommercial 4.0 International License (http://creativecommons.org/licenses/ by-nc/4.0/), which permits any noncommercial use, distribution, and reproduction in any medium, provided you give appropriate 
credit to the original author(s) and the source, provide a link to the Creative Commons license, and indicate if changes were made.

\section{REFERENCES}

1. Rachakonda T, Schupp C, Armstrong A. Psoriasis prevalence among adults in the United States. J Am Acad Dermatol. 2014;70(3):512-6.

2. Lebwohl MG, Bachelez H, Barker J, et al. Patient perspectives in the management of psoriasis: results from the population-based Multinational Assessment of Psoriasis and Psoriatic Arthritis Survey. J Am Acad Dermatol. 2014;70(5):871-81 (e1-30).

3. Feldman SR, Malakouti M, Koo JY. Social impact of the burden of psoriasis: effects on patients and practice. Dermatol Online J. 2014;20(8).

4. Roark CL, Simonian PL, Fontenot AP, Born WK, O'Brien RL. Gammadelta T cells: an important source of IL-17. Curr Opin Immunol. 2008;20(3): 353-7.

5. Weaver CT, Hatton RD, Mangan PR, Harrington LE. IL-17 family cytokines and the expanding diversity of effector $\mathrm{T}$ cell lineages. Annu Rev Immunol. 2007;25:821-52.

6. Krueger JG, Fretzin S, Suárez-Fariñas M, et al. IL-17A is essential for cell activation and inflammatory gene circuits in subjects with psoriasis. J Allergy Clin Immunol. 2012;130(1):145-54 (e9).

7. Chang SH, Dong C. A novel heterodimeric cytokine consisting of IL-17 and IL-17F regulates inflammatory responses. Cell Res. 2007;17(5): 435-40.

8. Laan M, Cui ZH, Hoshino $\mathrm{H}$, et al. Neutrophil recruitment by human IL-17 via C-X-C chemokine release in the airways. J Immunol. 1999;162(4): 2347-52.

9. Kao CYY, Chen Y, Thai P, et al. IL-17 markedly up-regulates beta-defensin-2 expression in human airway epithelium via JAK and NF-kappaB signaling pathways. J Immunol. 2004;173(5):3482-91.

10. Numasaki $M$, Fukushi J, Ono $M$, et al. Interleukin-17 promotes angiogenesis and tumor growth. Blood. 2003;101(7):2620-7.

11. Ariza MEE, Williams MV, Wong HK. Targeting IL-17 in psoriasis: from cutaneous immunobiology to clinical application. Clin Immunol. 2013;146(2): 131-9.

12. Lowes MA, Kikuchi T, Fuentes-Duculan J, et al. Psoriasis vulgaris lesions contain discrete populations of Th1 and Th17 T cells. J Invest Dermatol. 2008;128(5):1207-11.

13. Yilmaz SB, Cicek N, Coskun M, Yegin O, Alpsoy E. Serum and tissue levels of IL-17 in different clinical subtypes of psoriasis. Arch Dermatol Res. 2012;304(6):465-9.

14. Brown G, Malakouti M, Wang E, Koo J, Levin E. Anti-IL-17 phase II data for psoriasis: a review. J Dermatolog Treat. 2014;26(1):32-6.

15. Kagami S, Rizzo HL, Lee JJ, Koguchi Y, Blauvelt A. Circulating Th17, Th22, and Th1 cells are increased in psoriasis. J Invest Dermatol. 2010;130(5): 1373-83.

16. Gordon KB. Ixekizumab for treatment of moderate-to-severe plaque psoriasis: 60-week results from a double-blind phase 3 induction and randomized withdrawal study (UNCOVER-1). Presented at: 73rd Annual Meeting of the American Academy of Dermatology; San Francisco; 2015.

17. Griffiths C, Reich K, Lebwohl M, et al. Comparison of ixekizumab with etanercept or placebo in moderate-to-severe psoriasis (UNCOVER-2 and UNCOVER-3): results from two phase 3 randomised trials. The Lancet. 2015;386(9993):541-51.

18. Revicki DA, Willian MK, Menter A, Saurat JHH, Harnam N, Kaul M. Relationship between clinical response to therapy and health-related quality of life outcomes in patients with moderate to severe plaque psoriasis. Dermatology (Basel). 2008;216(3): 260-70.

19. Puel A, Cypowyj S, Bustamante J, et al. Chronic mucocutaneous candidiasis in humans with inborn errors of interleukin-17 immunity. Science. 2011;332(6025):65-8.

20. Boisson B, Wang C, Pedergnana V, et al. An ACT1 mutation selectively abolishes interleukin-17 responses in humans with chronic mucocutaneous candidiasis. Immunity. 2013;39 (4):676-86.

21. Gao S, Huang K, Tu H, Adler A. Monoclonal antibody humanness score and its applications. BMC Biotechnol. 2013;13(1):55.

22. Levin EC, Gupta R, Brown G, Malakouti M, Koo J. Biologic fatigue in psoriasis. J Dermatolog Treat. 2014;25(1):78-82. 
23. Harding FA, Stickler MM, Razo J, DuBridge RB. The immunogenicity of humanized and fully human antibodies: residual immunogenicity resides in the CDR regions. MAbs. 2010;2(3):256-65.

24. Salfeld JG. Isotype selection in antibody engineering. Nat Biotechnol. 2007;25(12):1369-72.

25. Langenbruch A, Radtke MA, Krensel M, Jacobi A, Reich K, Augustin M. Nail involvement as a predictor of concomitant psoriatic arthritis in patients with psoriasis. $\mathrm{Br} \mathrm{J}$ Dermatol. 2014;171(5):1123-8.

26. Mease PJ, McInnes IB, Kirkham B, et al. Secukinumab Inhibition of Interleukin-17A in Patients with Psoriatic Arthritis. N Engl J Med. 2015;373(14):1329-39.

27. Raychaudhuri SP. Role of IL-17 in psoriasis and psoriatic arthritis. Clin Rev Allergy Immunol. 2013;44(2):183-93.

28. Raychaudhuri SP, Raychaudhuri SK, Genovese MC. IL-17 receptor and its functional significance in psoriatic arthritis. Mol Cell Biochem. 2012; 359(1-2):419-29.

29. Eli Lilly and Company. Lilly's Ixekizumab met primary endpoint in a phase 3 study investigating the treatment of psoriatic arthritis. http://www. prnewswire.com/news-releases/lillys-ixekizumab-metprimary-endpoint-in-a-phase-3-study-investigatingthe-treatment-of-psoriatic-arthritis-300068249. html. PR Newswire, 2015. Accessed 21 Dec 2015.

30. Wu JJ, Poon KYTY, Channual JC, Shen AY. Association between tumor necrosis factor inhibitor therapy and myocardial infarction risk in patients with psoriasis. Arch Dermatol. 2012;148(11):1244-50.

31. De Boer OJ, van der Meer JJ, Teeling $\mathrm{P}$, et al. Differential expression of interleukin-17 family cytokines in intact and complicated human atherosclerotic plaques. J Pathol. 2010;220(4): 499-508.

32. Csiszar A, Ungvari Z. Synergistic effects of vascular IL-17 and TNFalpha may promote coronary artery disease. Med Hypotheses. 2004;63(4):696-8.

33. Hashmi S, Zeng QT. Role of interleukin-17 and interleukin-17-induced cytokines interleukin-6 and interleukin-8 in unstable coronary artery disease. Coron Artery Dis. 2006;17(8):699-706.

34. Gan EY, Chong WSS, Tey HL. Therapeutic strategies in psoriasis patients with psoriatic arthritis: focus on new agents. BioDrugs. 2013;27(4):359-73. 